\title{
PREPARO DE GOETHITAS DOPADAS COM TITÂNIO PARA REMOÇÃO DE RODAMINA B DO MEIO AQUOSO
}

\author{
Isabela Fontoura Neves ${ }^{1}$ \\ Samuel Onofre Nicoli ${ }^{2}$ \\ Ronan Facini Tessinari ${ }^{3}$ \\ Alexandre dos Santos Anastácio ${ }^{4}$
}

Resumo: Rejeitos industriais representam um importante problema ambiental. A grande quantidade de compostos orgânicos despejados em corpos d'água podem causar graves consequências como, por exemplo, a queda de oxigênio dissolvido nos recursos hídricos, o que provoca um desequilibrio ao ecossistema aquático. A rodamina B é de difícil degradação, sendo os processos oxidativos avançados uma alternativa interessante para a diminuição de sua carga orgânica em efluentes. Dentre estes processos, o fenton heterogêneo tem se destacado bastante por sua aplicabilidade e custo relativamente baixo. Neste trabalho, óxidos de ferro (goethitas) dopados com titânio 5\% foram preparados a partir da hidrólise dos sais precursores e caracterizados por difratometria de raios- $X$. Posteriormente, esses materiais foram testados para degradação da rodamina $B$ utilizando o processo conhecido como fenton heterogêneo. Os resultados indicaram que o único óxido de ferro formado foi a goethita não havendo coexistência de outras fases de ferro nem formação de óxido de titânio. Para os testes catalíticos, houve maior eficiência para a goethita a $5 \%$ de titânio.

Palavras-chave: Goethita; Reação tipo-fenton; Rodamina B.

\footnotetext{
${ }^{1}$ Química/UFES, Brasil. E-mail: bela-fontoura@hotmail.com.

2 Química/UFES, Brasil. E-mail: samuellnicoli@gmail.com.

${ }^{3}$ Laboratório de Ciências Naturais/UENF-CCT, Brasil. E-mail: ronanft@gmail.com.

4 Departamento de Química e Física/UFES, Brasil. E-mail: asanastacio@gmail.com.
} 